\title{
BMJ Open Life satisfaction, job satisfaction, life orientation and occupational burnout among nurses and midwives in medical institutions in Poland: a cross-sectional study
}

\author{
Izabella Uchmanowicz, ${ }^{\oplus}$ Stanisław Manulik, ${ }^{2}$ Katarzyna Lomper, ${ }^{1}$ \\ Anna Rozensztrauch, ${ }^{3}$ Agnieszka Zborowska, ${ }^{1}$ Jolanta Kolasińska, ${ }^{1}$ \\ Joanna Rosińczuk ${ }^{2}$
}

To cite: Uchmanowicz I, Manulik S, Lomper K, et al. Life satisfaction, job satisfaction, life orientation and occupational burnout among nurses and midwives in medical institutions in Poland: a crosssectional study. BMJ Open 2019;9:e024296. doi:10.1136/ bmjopen-2018-024296

- Prepublication history for this paper is available online. To view these files, please visit the journal online (http://dx.doi. org/10.1136/bmjopen-2018024296).

Received 19 May 2018 Revised 5 December 2018 Accepted 18 December 2018

\section{Check for updates}

(C) Author(s) (or their employer(s)) 2019. Re-use permitted under CC BY-NC. No commercial re-use. See rights and permissions. Published by BMJ.

${ }^{1}$ Department of Clinical Nursing, Faculty of Health Sciences, Wroclaw Medical University, Wroclaw, Poland

${ }^{2}$ Department of Nervous System Diseases, Faculty of Health Sciences, Wroclaw Medical University, Wroclaw, Poland ${ }^{3}$ Department of Neonatology, Faculty of Health Sciences, Wroclaw Medical University, Wroclaw, Poland

\section{Correspondence to}

Professor Izabella Uchmanowicz; izabella.uchmanowicz@eckp. wroclaw.pl

\section{ABSTRACT}

Objectives To assess life satisfaction, job satisfaction, life orientation and the level of professional burnout in a group of professionally active nurses and midwives.

Design A cross-sectional study.

Setting This study was conducted between March and October of 2017 during specialisation training at the European Centre for Postgraduate Education in Wroclaw, Poland.

Participants A group of 350 professionally active nurses $(n=293)$ and midwives $(n=57)$ were enrolled in the study. Outcome measures Associations between burnout and selected life-related and job-related outcomes using (1) the Satisfaction With Job Scale, (2) the Satisfaction With Life Scale (SWLS), (3) the Life Orientation Test-Revised, (4) the Maslach Burnout Inventory and the Authors' Designed Questionnaire regarding sociodemographic factors. The level of statistical significance was set at $p \leq 0.05$ (with a Cl of $95 \%)$.

Results The vast majority of participants were those in the ages of $41-50$ years old (40.57\%), women (96.86\%) and people with bachelor's degree (46.29\%). The average overall rate for occupational burnout was 34.67 per 100 points. Assessment of occupational burnout subscale showed that the most significant factor was emotional exhaustion at 39.14 points $(S D=28.15)$. Job satisfaction, life satisfaction and life orientation assessed with SWLS significantly affects each of the occupational burnout subscales $(p<0.05)$.

Conclusions The level of occupational burnout in nurses and midwives appeared to be low. It has been revealed that such determinants as life satisfaction, job satisfaction and life orientation do not allow for developing an occupational burnout.

\section{INTRODUCTION}

Occupational activity is an essential aspect of life for the majority of people, and as a source of satisfaction, it can contribute to an increase in overall life satisfaction. According to the literature, job satisfaction is associated
Strengths and limitations of this study

- Our study is one of the first to quantitatively assess the occupational burnout among Polish nurses and midwives, considering the selected life-related and job-related outcomes.

- We used well-established and standardised tools to address burnout phenomenon in this population of healthcare providers.

- The professional group of midwives was also included in the study, which is an additional strength, and the entire study was conducted on a large group of 350 subjects.

- The study lacks of an external control group. Also, group division into two subgroups midwives and nurses was not provided. Such presentation of differences or similarities in wide range of variables studied between these professional groups could be an additional asset of the study.

with the individual's ability to pursue goals, values and beliefs. ${ }^{1}$

While an increase in satisfaction contributes to a greater or lesser extent to an employee's commitment and efficiency, a decrease in satisfaction increases the risk of unfavourable phenomena, such as increased absenteeism or changing jobs. ${ }^{23}$ Some researchers postulate that one should not distinguish the various negative effects of dissatisfaction but should treat them as one factor. ${ }^{4}$

Among the factors affecting job satisfaction are listed professional achievements, chances for higher qualifications and the appreciation of superiors. ${ }^{5}$ Professional satisfaction among Polish nurses is widely described in the literature as an important predictor affecting the quality of the provided healthcare services. The nurse, who is working in a profession 
of public trust, is exposed to stressful factors related to health protection and saving human lives. Permanent difficult and stressful situations and the mental and physical exhaustion that often accompanies nursing can contribute to a lack of motivation, indifference and even illness. $^{6-8}$

As a result of constant stress, nurses may experience a 'burnout syndrome', which negatively affects not only the nurse but also the patients in their care. ${ }^{910}$ The concept of occupational burnout itself reflects a social problem that has been escalating in recent years, the description of which was created very spontaneously. Burnout is a psychological syndrome emerging as a prolonged response to chronic interpersonal stressors on the job. ${ }^{11}$ It involves feelings of emotional exhaustion, depersonalisation and diminished personal accomplishment at work. ${ }^{12}$

One of the factors directly related to the occurrence of occupational burnout is satisfaction with life. There are many definitions of 'life satisfaction' in the literature; however, they are not equivalent in meaning. It is assumed that this concept refers to the successful ageing and positive self-assessment of living conditions, which can also be an indicator of general well-being. ${ }^{13}$

Some researchers have conceptualised burnout according to potential sources of psychological fatigue such as personal, client and work-related domains. ${ }^{14}$ The phenomenon of occupational burnout results from experiencing increased anxiety or the lack of expected results of activities for a long time. ${ }^{15}$ The phenomenon of occupational burnout does not cover all professional groups and exists especially where close interpersonal contact requires full involvement. ${ }^{16}$

Occupational burnout is not a consequence of one event, but it is the result of slowly debilitating processes. The phenomenon of occupational burnout develops gradually and progresses as a result of unbalanced interactions between the expectations of people and their ability to bear burdens. Factors influencing the occurrence of burnout include individual factors such as sex, age, the level of endurance and commitment, the level of self-esteem, the nature of work and professional beliefs. ${ }^{17}$ The second group of factors which foster the emergence of burnout syndrome are situational factors such as time pressure, a lack of social support, a lack of autonomy, conflicts, work intensity, a lack of a sense of reciprocity and a hierarchy. ${ }^{18}$

The available literature indicates that occupational burnout significantly affects the temperament of employees, leads to their inaction and contributes to a reduced quality of services. ${ }^{19}{ }^{20}$ Moreover, medical staff may experience emotional instability, a decreased willingness to work and growing irritation. ${ }^{21}{ }^{22}$ Significant psychological burdens and constant frustration resulting from work fatigue are predictors of occupational burnout risk in a group of nurses.

In the available literature on the subject, there are reports regarding life satisfaction, job satisfaction and occupational burnout in the professional nurses. There
Table 1 Sociodemographic characteristics of study participants $(n=350)$

\begin{tabular}{lcc}
\hline Character & N & $\%$ \\
\hline Age & & \\
\hline 23-30years & 92 & 26.29 \\
\hline 31-40years & 142 & 14.29 \\
\hline 41-50years & 61 & 40.57 \\
\hline 51-60years & 5 & 17.43 \\
\hline 61 years and more & 1.43 \\
\hline Sex & 339 & \\
\hline Female & 11 & 36.86 \\
\hline Male & & \\
\hline Education & 67 & 19.14 \\
\hline Medical high school & 28 & 8.00 \\
\hline Medical college of further & & \\
\hline education & 162 & 46.29 \\
\hline Bachelor & 90 & 25.71 \\
\hline Master & 3 & 0.86 \\
\hline Other & & \\
\hline
\end{tabular}

are still few studies focusing on burnout phenomenon among midwives. Therefore, the aim of the study was to assess life satisfaction, job satisfaction, life orientation and the level of occupational burnout in a group of professionally active nurses and midwives.

Early detection of the phenomenon of occupational burnout is an indispensable element of social and environmental support for healthcare providers. Actions should be taken to reduce long-term depression resulting from the specifics of the nurses and midwives job.

\section{MATERIAL AND METHODS}

\section{Study design and settings}

A cross-sectional, descriptive, analytical design using a questionnaire was employed for this study. Study design and reporting format are in accordance with the recommended Strengthening the Reporting of Observational Studies in Epidemiology guidelines for observational clinical studies. The study was conducted in a group of 350 professionally active nurses $(n=293)$ and midwives $(n=57)$ and included 11 men. Detailed characteristics of the study participants are shown in table 1 and table 2 . This study was conducted between March and October of 2017 during specialisation training for nurses and midwives at the European Centre for Postgraduate Education in Wroclaw, Poland.

\section{Recruitment}

Participation in the study was anonymous and voluntary. Recruitment procedure was carried out by contacting professionally active nurses and midwives and inviting them to participate in specialisation training at the European Centre for Postgraduate Education in Wroclaw, 


\begin{tabular}{|c|c|c|}
\hline $\begin{array}{l}\text { Table } 2 \text { Occupational chara } \\
(\mathrm{n}=350)\end{array}$ & ics of & participants \\
\hline Character & $\mathbf{N}$ & $\%$ \\
\hline \multicolumn{3}{|l|}{ Occupation } \\
\hline Nurse & 293 & 83.71 \\
\hline Midwife & 57 & 16.29 \\
\hline \multicolumn{3}{|l|}{ Work experience } \\
\hline $0-5$ years & 89 & 25.43 \\
\hline $6-10$ years & 36 & 10.29 \\
\hline $11-15$ years & 17 & 4.86 \\
\hline $16-20$ years & 41 & 11.71 \\
\hline 21 years and more & 167 & 47.71 \\
\hline \multicolumn{3}{|l|}{ Main place of work } \\
\hline Hospital & 311 & 88.86 \\
\hline Open care & 23 & 6.57 \\
\hline Other & 16 & 4.57 \\
\hline \multicolumn{3}{|l|}{ Working system } \\
\hline 8 hours (07:00-15:00) & 77 & 22.00 \\
\hline $\begin{array}{l}12 \text { hours }(07: 00-19: 00 \text { and } \\
19: 00-07: 00)\end{array}$ & 258 & 73.71 \\
\hline Other & 15 & 4.29 \\
\hline \multicolumn{3}{|l|}{ Monthly net salary } \\
\hline 1000-2000 PLN & 55 & 15.71 \\
\hline 2001-3000 PLN & 201 & 57.43 \\
\hline $3001-4000$ PLN & 69 & 19.71 \\
\hline 4001-5000 PLN & 17 & 4.86 \\
\hline 5001-6000 PLN & 4 & 1.14 \\
\hline 6001 PLN and more & 4 & 1.14 \\
\hline
\end{tabular}

Poland. Contact was established via telephone, email and regular mail providing information on the study objectives. The inclusion criteria to participate in the study were: having a permit to practice nursing and being a registered nurse, having current professional activity, giving consent to participate in the study and being over the age of 18 .

\section{Ethical considerations and permissions}

The study protocol was approved. The study was carried out in accordance with the Declaration of Helsinki guidance of the World Medical Association and Good Clinical Practice recommendations. All subjects gave their informed consent for inclusion before they participated in the study. They were informed of its purpose and course, and of the possibility of withdrawing from the study at any stage. This study was conducted under a research project funded by the Ministry of Science and Higher Education in Poland as a part of a statutory grant of the Wroclaw Medical University for maintaining research potential (no. ST.E020.17.050).

\section{Data collection and research tools}

All participants received five questionnaires. These consisted of a sociodemographic questionnaire (SDQ) designed by the authors, as well as standardised questionnaire tools which had been previously validated and adapted to Polish conditions: Satisfaction With Job Scale (SWJS), Life Orientation Test-Revised (LOT-R) and Maslach Burnout Inventory (MBI).

\section{Sociodemographic questionnaire}

The first part consisted of questions pertaining to the population group-age, gender, level of education, marital status and place of residence. The second part dealt with occupational data such as profession, level of experience, main place of work, work system in hours per day and net salary per month.

\section{Satisfaction With Job Scale}

The SWJS allows for the assessment of the sense of life satisfaction. The final result of the SWJS is the total number of points derived from five questions (the range is 5-35 points). Higher scores indicate greater job satisfaction. There are no standards for the SWJS questionnaire which determine whether the obtained result is high or low. The SWJS scale has a so-called 'centre point' that is set at 20 points (four points per question), meaning that the participant is neither happy nor dissatisfied with his or her work..$^{23} 24$

\section{Satisfaction With Life Scale}

The Satisfaction With Life Scale (SWLS) scale is used for subjective assessment of the sense of life satisfaction and is a research tool that can be used for the examination of both patients and healthy people. It is a five-item scale designed to measure global cognitive judgements of one's life satisfaction (not a measure of either positive or negative affect). The results between 1 and 4 sten score determine the lower sense of life satisfaction, 5 and 6 as average and from 7 to 10 as high. ${ }^{25} 26$

\section{Life Orientation Test-Revised}

The LOT-R test allows assessing the life orientation of the study participants. The results of LOT-R in the study were converted into sten scores, in accordance with the applicable standards given in the key to this questionnaire. The results between 1 and 4 indicate a low level of optimism (ie, a tendency to pessimism), 5-6 indicate the average level of optimism (ie, neutral attitude) and the results $7-10$ shows a high level of optimism (ie, the tendency to optimism). ${ }^{2728}$

\section{Maslach Burnout Inventory}

The MBI is the most commonly used tool to assess the risk of burnout. It consists of 22 items related to three aspects of occupational burnout: emotional exhaustion (EE), depersonalisation (DEP) and personal accomplishment (PA). The results on each of these subscales are expressed on a scale of $0-100$, where a higher score means a higher level of professional burnout. In addition, the overall 
burnout rate is also calculated, being the average of three subscales. High scores in the subscales of EE and DEP and low sense of PA in the subscale allow to state that the examined person is burned out occupationally. ${ }^{29} 30$

\section{Statistical analyses}

The analysis of each quantitative variable was conducted by calculating the mean $(\mathrm{M})$, SD, median $(\mathrm{Me})$, lower (Q1) and upper quartile (Q3) and minimum (Min) and maximum (Max) values. The normality of empirical distribution of quantitative variables was verified by the Shapiro-Wilk test. Correlations between quantitative variables were analysed using a Spearman correlation coefficient (due to non-normality of analysed variables).

Correlation coefficients were interpreted as follows: $|r| \geq 0.9$-very strong correlation; $0.7 \leq|r|<0.9$-strong correlation; $0.5 \leq|\mathrm{r}|<0.7$-moderately strong correlation; $0.3 \leq|r|<0.5$ - weak correlation; $|r| \geq 0.3$ —very weak (negligible) correlation. Statistical analysis was performed using the R software, V.3.4.3. The level of statistical significance was set at $\mathrm{p} \leq 0.05$ (with a CI of $95 \%$ ).

\section{Patient and public involvement}

Patients and public were not involved in the study.

\section{RESULTS}

\section{Analysis of sociodemographic data}

The most numerous age group among the study participants $(\mathrm{n}=350)$ was the group of $41-50(40.57 \%)$ and 23-30-year-olds $(26.29 \%)$. The vast majority of participants are women $(96.86 \%)$ and people with bachelor's degree $(46.29 \%)$ and master's degree (25.71\%) (table 1$)$.

\section{Analysis of occupational data}

Based on the analysis of data on the professional work of the studied participants $(n=350)$, it was observed that the largest group were nurses $(83.71 \%)$ in comparison to the midwives (16.29\%). Taking into account the work experience, the group most often indicated the answer '21 years and more' $(47.71 \%)$ and ' $0-5$ years' (25.43\%). The main place of work was closed care-the hospital $(88.86 \%)$ and the basic contract among the surveyed participants was an employment contract $(84.00 \%)$. As a working system, the shift system $(73.71 \%)$ and work in the 8-hour period $(22.00 \%)$ were most often indicated. Based on the data analysis of monthly net salary, it was observed that the most frequently indicated salary was the range of 2001-3000 PLN which ranges about 585-880 USD (57.43\%) and 3001-4000 PLN which ranges about 880-1170 USD (19.71\%) (table 2).

\section{Assessment of job satisfaction (SWJS)}

The average score obtained by the participants in the SWJS questionnaire was $19.76(\mathrm{SD}=5.36, \mathrm{M}=20, \mathrm{Min}=6$, $\mathrm{Max}=35, \mathrm{Q} 1=16, \mathrm{Q} 3=23.94$ ), where the score of 20 is considered a 'center point'. It can, therefore, be discussed that the participants are neither satisfied nor dissatisfied with their work.

\section{Assessment of life satisfaction (SWLS)}

Based on the assessment of the results obtained in the SWLS questionnaire, it was observed that 160 participants (46\%) were high, 128 participants (37\%) average and 62 participants (18\%) low sense of life satisfaction.

\section{Assessment of life orientation (LOT-R)}

The analysis of the results of the LOT-R questionnaire showed that 131 participants $(37.43 \%)$ had a neutral orientation, 130 participants $(37.14 \%)$ were prone to optimism and 89 participants $(25.43 \%)$ were prone to pessimism.

\section{Assessment of occupational burnout (MBI)}

The results of the analysis of the MBI questionnaire showed that the average overall rate for occupational burnout was 34.67 per 100 points. Assessment of occupational burnout subscale showed that the most significant factor was $\mathrm{EE}$ at 39.14 points $(\mathrm{SD}=28.15, \mathrm{M}=33.33$, $\mathrm{Min}=0$, Max=100, $Q 1=11.11, Q 3=65.62$ ), a slightly smaller was PA at 35.44 points $(\mathrm{SD}=27.22, \mathrm{M}=26.79, \mathrm{Min}=0, \mathrm{Max}=96.3$, $\mathrm{Q} 1=12.5, \mathrm{Q} 3=50)$ and in the smallest was DEP of 29.41 points $(\mathrm{SD}=27.95, \quad \mathrm{M}=20, \quad \mathrm{Min}=0, \quad \mathrm{Max}=96.3, \quad \mathrm{Q} 1=0$, $\mathrm{Q} 3=40)$.

\section{Impact of each scales on the level of occupational burnout}

Further analysis was performed to determine the impact of job satisfaction on the level of occupational burnout. The SJWS result did not have a normal distribution $(\mathrm{p}<0.05$ in the Shapiro-Wilk test), so the Spearman correlation coefficient was used for the analysis. It was shown that job satisfaction significantly affects each of the occupational burnout subscales $(\mathrm{p}<0.05)$. These dependencies are negative, that is, the greater job satisfaction, the less sense of professional burnout (table 3 and figure 1).

Table 3 Spearman's correlation coefficient analysis for the level occupational burnout and job satisfaction

\begin{tabular}{|c|c|c|c|c|}
\hline \multirow[b]{2}{*}{ MBI } & \multicolumn{4}{|c|}{ Correlation with Satisfaction With Job Scale } \\
\hline & Correlation coefficient & $P$ value & Direction & Strength \\
\hline Emotional exhaustion & -0.489 & $<0.001$ & Negative & Weak \\
\hline Reduced personal accomplishment & -0.447 & $<0.001$ & Negative & Weak \\
\hline Overall score & -0.474 & $<0.001$ & Negative & weak \\
\hline
\end{tabular}



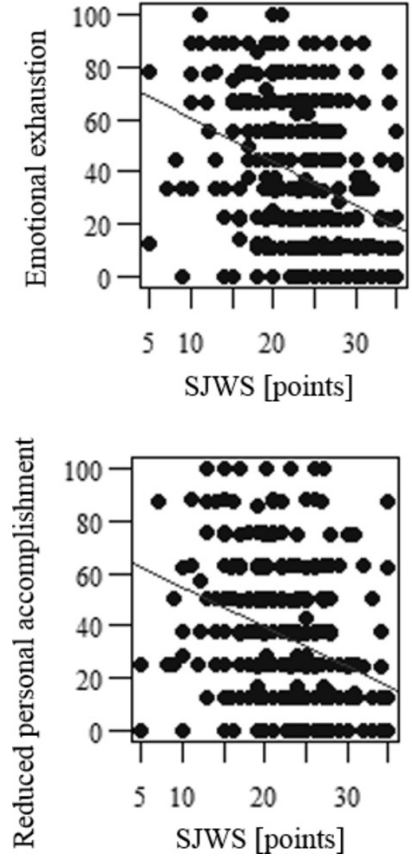
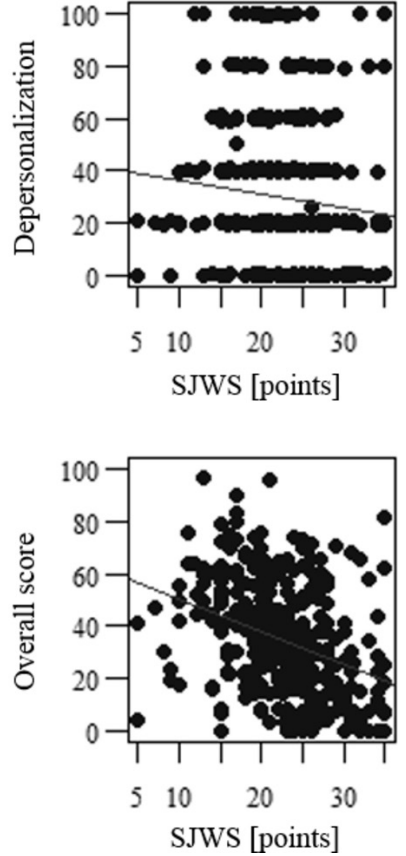

Figure 1 The linear correlation between job satisfaction and domains of the occupational burnout. SWJS, Satisfaction With Job Scale.

Further analysis was performed to determine the impact of life satisfaction on the level of occupational burnout. It has been shown that life satisfaction assessed with SWLS significantly affects each of the occupational burnout subscales $(p<0.05)$. These dependencies are negative, that is, the greater the life satisfaction, the lower the sense of burnout (table 4 and figure 2).

Further analysis was performed to determine the impact of life orientation on the level of occupational burnout. It was observed that life orientation significantly influences each of the occupational burnout subscales $(p<0.05)$. These dependencies are negative, that is, the higher the LOT-R score (greater propensity to optimism), the lower the sense of burnout (table 5 and figure 3 ).

\section{DISCUSSION}

Because of their close contact with others, nurses and midwives hold professions of great social importance. Everyday work under changing conditions, high degrees of mental and physical stress and shift work may lead to development of burnout syndrome in these professionals.
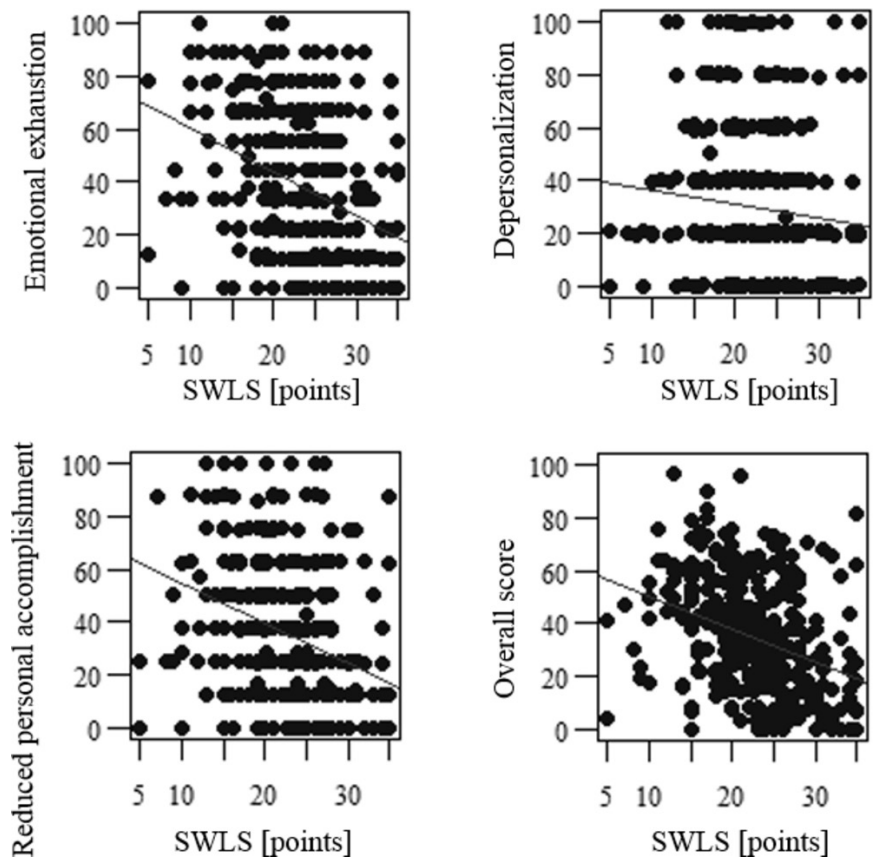

Figure 2 The linear correlation between life satisfaction and domains of the occupational burnout. SWLS, Satisfaction With Life Scale.

In one of the most common definitions of professional burnout, special attention is paid to emotional exhaustion, which is treated as one of the first symptoms of this phenomenon. $^{3132}$

The relationship between occupational burnout and the performance of professionals who provide assistance to others has been documented in recent studies. ${ }^{33}$ However, it is emphasised in the literature that this phenomenon most often concerns medical professionals, especially nurses. ${ }^{34}$ Analysis of burnout among various medical professionals, that is, doctors, pharmacists and nurses, revealed that burnout is most often commonly found in nursing staff. ${ }^{36}$

Based on available scientific reports, this paper attempts to determine the extent of the burnout problem among nurses and midwives and to assess the levels of job satisfaction among these professionals. This study involved a group of 350 professionally active nurses and midwives at various workplaces, that is, closed care and open care. The obtained results indicate a disturbing phenomenon related to the age demographics among medical

Table 4 Spearman's correlation coefficient analysis for the level occupational burnout and life satisfaction

\begin{tabular}{|c|c|c|c|c|}
\hline \multirow[b]{2}{*}{ Maslach Burnout Inventory } & \multicolumn{4}{|c|}{ Correlation with Satisfaction With Life Scale } \\
\hline & Correlation coefficient & $P$ value & Direction & Strength \\
\hline Emotional exhaustion & -0.36 & $<0.001$ & Negative & weak \\
\hline Reduced personal accomplishment & -0.35 & $<0.001$ & Negative & weak \\
\hline Overall score & -0.371 & $<0.001$ & Negative & weak \\
\hline
\end{tabular}


Table 5 Spearman's correlation coefficient analysis for the level occupational burnout and life orientation

\begin{tabular}{lllll} 
& \multicolumn{4}{l}{ Correlation with Life Orientation Test-Revised } \\
\cline { 2 - 5 } Maslach Burnout Inventory & Correlation coefficient & P value & Direction & Strength \\
\hline Emotional exhaustion & -0.32 & $<0.001$ & Negative & Weak \\
Depersonalisation & -0.147 & 0.006 & Negative & Very weak \\
Reduced personal accomplishment & -0.325 & $<0.001$ & Negative & Weak \\
Overall score & -0.337 & $<0.001$ & Negative & Weak \\
\hline
\end{tabular}

staff, including nurses. In our study, the majority of the surveyed participants were over 40 years of age.

Currently, both nursing and midwifery in Poland are professions dominated by ageing workers. Moreover, there is a declining interest in these medical professions among young women and men. ${ }^{637}$

There are studies suggesting that a high level of education affects the rate of occupational burnout. People with more education are more likely to have high expectations of themselves and to take on more responsibility and more demanding positions at work. ${ }^{38}$ It should also be noted that a shift system is associated with lowered quality of life and may pose safety risks for patients as well as nurses. ${ }^{20}{ }^{39}$ Long 12-hour shifts and irregular working hours are considered risk factors for the development of occupational burnout. ${ }^{40}$

Job satisfaction is one of the main factors determining the attitude of medical staff towards work and patients and affecting the quality of services provided. Job satisfaction is a general, positive assessment of work, in which some negative factors cannot be excluded. ${ }^{41} 42$ Factors that positively influence job satisfaction include high income,
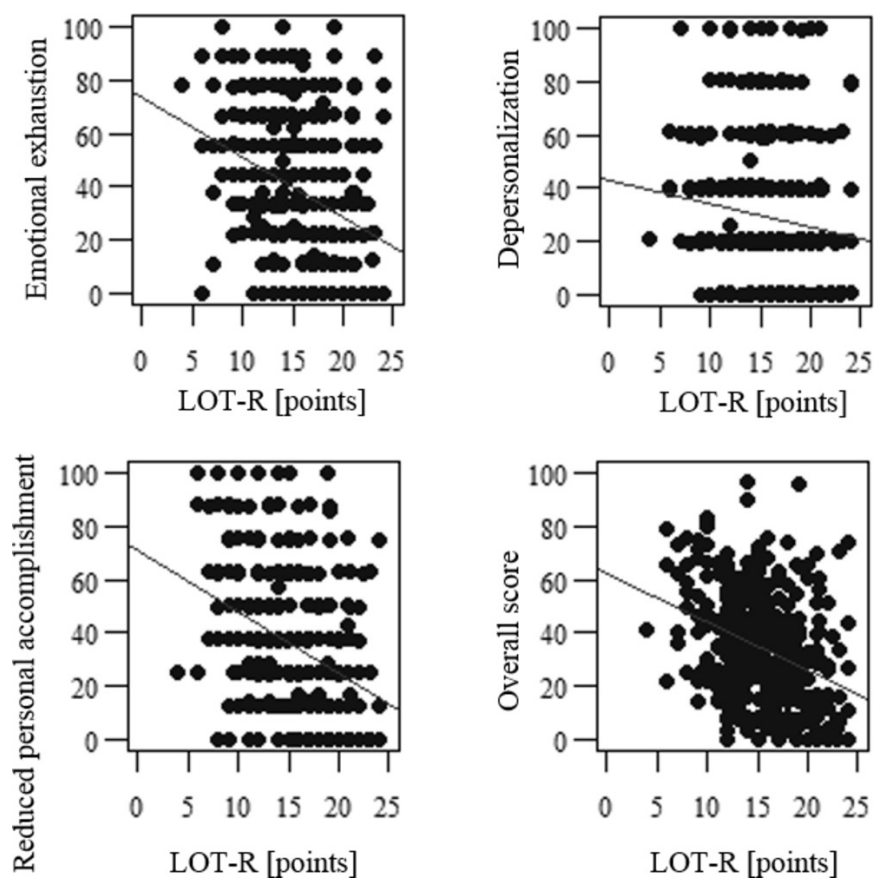

Figure 3 The linear correlation between life orientation and domains of the occupational burnout. LOT-R, Life Orientation Test-Revised. professional prestige and younger employee age. ${ }^{43}$ Interestingly, Güleryüz et $a l^{44}$ identify emotional intelligence as a positive factor influencing job satisfaction in nurses. On the other hand, negative factors include excessive professional expectations. ${ }^{45}$ In a study by Kędra et $a l^{46}$ negative influences on job satisfaction also included an excess of duties and demanding requirements at work. Moreover, among the less important factors were listed shortcomings of cooperation at the nurse-doctor level and between nurses and other medical personnel. Also, Applebaum $e t a l^{47}$ in their descriptive, correlational study revealed that common environmental stressors in the work environment can be stressful to staff and influence job satisfaction and, ultimately, intention to change jobs. In our study, the average job satisfaction levels of participants were noted based on the analysis of the results of the SJWS questionnaire.

Life satisfaction is a component of quality of life. Several factors can affect one's level of life satisfaction, including personality traits, life events and one's current mood. ${ }^{48}$ The relationship between level of life satisfaction and job satisfaction in the nursing environment has been documented in the literature. ${ }^{49} 50$ The results obtained by us indicate that almost half of the participants had a high sense of life satisfaction according to the SWLS questionnaire. In the study by Wysokiński $e t a l^{\tilde{1}}$ carried out on a group of 891 nurses, the average level of life satisfaction according to the SWLS questionnaire was 19.60 points. The available literature indicates that a higher level of life satisfaction is achieved by people in committed relationships. Our study group consists mostly of nurses and midwives in committed relationships, so this study confirms worldwide reports. ${ }^{52} 53$

The role of nurses and midwives is to provide help and care and to participate in the recovery of each patient. Nursing forces staff to be emotionally involved in their work, and this high level of emotional involvement can lead to fatigue, exhaustion, frustration and, consequently, burnout syndrome.

An analysis of the levels of occupational burnout among the study participants demonstrated that half of them had occupational burnout at the lower level, and half had burnout scores higher than 33.38 points. Thus, an average level of occupational burnout was observed among the studied nurses and midwives. The present study presents similar results to those in the available literature. Average results for burnout in the MBI questionnaire among 
nurses were also demonstrated by Klajda and Szewczyk, ${ }^{54}$ who also showed the highest degree of nurse burnout at the emotional level. In our study, the assessment of the MBI questionnaire subscales showed that the primary determinant of occupational burnout scores was level of $\mathrm{EE}$, followed by lack of PA and DEP.

Also, Piko et a $\tilde{p}^{55}$ noted the highest level of occupational burnout at the emotional level in a group of Hungarian nurses. It was also observed that emotional exhaustion was strongly related to job dissatisfaction, which is a risk factor for occupational burnout. The analysis of our own research brings us to the conclusion that job satisfaction significantly affects each of the occupational burnout subscales. A significant relationship between occupational burnout and life satisfaction and life orientation was also noted. Higher levels of life satisfaction and higher life orientation scores (ie, a greater tendency to optimism) were significantly associated with lower levels of burnout.

The nurse and midwife professions require a lot of commitment to working with and caring for patients. High emotional involvement, everyday contact with patients in various stages of disease, shift work and high levels of stress can take a huge physical and mental toll, leading to the development of burnout symptoms. The multitasking nature of nurse and midwife professions, a specific organisational structure, shift work, long working hours, poor infrastructure, inadequate resources, limited equipment and materials, as well as a shortage of staff, can also be risk factors for the burnout syndrome.

In summary, this cross-sectional, descriptive, analytical study among a group of 350 professionally active nurses and midwives in Poland assessing the life satisfaction, job satisfaction, life orientation and the level of occupational burnout. What is new, this is one of the few studies in Poland. An analysis of the levels of occupational burnout among the studied nurses and midwives demonstrated that half of them had occupational burnout at the lower level; thus, an average level of occupational burnout was observed. Also, a significant relationship between occupational burnout and life satisfaction and life orientation was also noted; the higher levels of life satisfaction and orientation were significantly associated with lower levels of burnout. We confirmed that burnout is still an important phenomenon in the healthcare system because employees are exposed to stress in both the mental and emotional spheres, as well as there is a need for further research, which will cover the aspects of mechanisms for the development of burnout syndrome.

\section{Limitations}

There are some potential limitations for this study that should be mentioned. First of all, the study lacks of an external control group, which would be valuable to compare the obtained results of burnout with controls. Also, study group could be divided into two comparative groups of nurses and midwives regarding selected specifications of their professional activities. Such presentation of differences or similarities in wide range of variables studied between these professional groups could be an additional asset of the study. And the last but not least, an interest would be to compare burnout levels obtained in our study with nurses from other units such as oncology, primary care, emergency or paediatrics.

\section{Practical implications}

Recently, there has been a growing interest in the phenomenon of occupational burnout among medical staff, in particular in the group of nurses and midwives. Burnout is an important phenomenon in the healthcare system because employees are exposed to stress in both the mental and emotional spheres. There is a need for further research, which will cover the aspects of mechanisms for the development of burnout syndrome and highlight the main factors affecting its progress.

Particularly important for the prevention of burnout is the improvement of the working environment, finding free time for staff, learning how to manage stress or even remunerating employees for improving their professional qualifications. ${ }^{56}$ Also the importance of creation the role of so-called the clinical career leadership among nurses should be emphasised. Changes in the healthcare system may have a positive impact on their sensations towards professional life ${ }^{57}$ Burnout clearly impacts on the mental health and well-being of nurses, which is most likely compromising productivity, performance and the quality of patient care and may lead to rationing of care.

\section{CONCLUSIONS}

The level of occupational burnout appeared to be low in the examined group of the Polish nurses and midwives. It has been revealed that job satisfaction and life satisfaction are determinants, which do not allow for developing an occupational burnout.

Acknowledgements The certificated English language services were provided by an academic highly qualified native English speaker to eliminate possible grammatical or spelling errors and to conform to correct scientific English.

Contributors IU, KL, AR and JR planned the study. IU and JR supervised the study. $\mathrm{SM}, \mathrm{KL}$ and $\mathrm{AR}$ analysed the data. IU, AZ-D and JK drafted the manuscript. All authors contributed substantially to its revision. IU takes responsibility for the paper as a whole. All authors read and approved the final manuscript.

Funding That study was conducted under a research project funded by the Ministry of Science and Higher Education in Poland as part of a statutory grant of the Wroclaw Medical University for maintaining research potential (no. ST.E020.17.050).

Competing interests None declared.

Patient consent for publication Not required.

Ethics approval The study was approved by the Independent Bioethics Committee of the Wroclaw Medical University, Poland.

Provenance and peer review Not commissioned; externally peer reviewed.

Data sharing statement The authors confirm that all data underlying the findings described in this manuscript is fully available to all interested researchers upon request.

Open access This is an open access article distributed in accordance with the Creative Commons Attribution Non Commercial (CC BY-NC 4.0) license, which permits others to distribute, remix, adapt, build upon this work non-commercially, and license their derivative works on different terms, provided the original work is 
properly cited, appropriate credit is given, any changes made indicated, and the use is non-commercial. See: http://creativecommons.org/licenses/by-nc/4.0/.

\section{REFERENCES}

1. Gallagher M, Muldoon OT, Pettigrew J. An integrative review of social and occupational factors influencing health and wellbeing. Front Psychol 2015;6.

2. Salvagioni DAJ, Melanda FN, Mesas AE, et al. Physical, psychological and occupational consequences of job burnout: A systematic review of prospective studies. PLoS One 2017;12:e0185781.

3. Stengård J, Bernhard-Oettel C, Berntson E, et al. Stuck in a job: being "locked-in" or at risk of becoming locked-in at the workplace and well-being over time. Work Stress 2016;30:152-72.

4. Qian J, Song B, Wang B. Abusive supervision and job dissatisfaction: the moderating effects of feedback avoidance and critical thinking. Front Psychol 2017;8.

5. Roelen CA, Koopmans PC, Groothoff JW. Which work factors determine job satisfaction? Work 2008;30:433-9.

6. Jaracz M, Rosiak I, Bertrand-Bucińska A, et al. Affective temperament, job stress and professional burnout in nurses and civil servants. PLoS One 2017;12:e0176698.

7. Orzechowska A, Talarowska M, Drozda R, et al. [The burnout syndrome among doctors and nurses]. Pol Merkur Lekarski 2008;25:507-9.

8. Lewandowska A, Litwin B. [Burnout as an occupational risk for nurses]. Ann Acad Med Stetin 2009;55:86-9.

9. McHugh MD, Kutney-Lee A, Cimiotti JP, et al. Nurses' widespread job dissatisfaction, burnout, and frustration with health benefits signal problems for patient care. Health Aff 2011;30:202-10.

10. Kulkarni P, Kulkarni $P$, Ghooi R, et al. Stress among care givers: the impact of nursing a relative with cancer. Indian J Palliat Care 2014;20:31-9.

11. Maslach C, Leiter MP. Understanding the burnout experience: recent research and its implications for psychiatry. World Psychiatry 2016;15:103-11.

12. Montero-Marín J, García-Campayo J, Mosquera Mera D, et al. A new definition of burnout syndrome based on Farber's proposal. $J$ Occup Med Toxicol 2009;4:31.

13. Prason R, Chaturvedi KR. Life satisfaction: a literature review. Int $J$ Manag Humanit Soc Sci 2016;1:25-32.

14. Creedy DK, Sidebotham M, Gamble J, et al. Prevalence of burnout, depression, anxiety and stress in Australian midwives: a crosssectional survey. BMC Pregnancy Childbirth 2017;17:13.

15. Trifiletti E, Pedrazza M, Berlanda S, et al. Burnout disrupts anxiety buffer functioning among nurses: a three-way interaction model. Front Psychol 2017;8.

16. Ribeiro VF, Filho CF, Valenti VE, et al. Prevalence of burnout syndrome in clinical nurses at a hospital of excellence. Int Arch Med 2014;7:22.

17. Raftopoulos V, Charalambous A, Talias M. The factors associated with the burnout syndrome and fatigue in Cypriot nurses: a census report. BMC Public Health 2012:12:457.

18. Rozo JA, Olson DM, Thu HS, et al. Situational factors associated with burnout among emergency department nurses. Workplace Health Saf 2017;65:262-5.

19. Darban F, Balouchi A, Narouipour A, et al. Effect of communication skills training on the burnout of nurses: a cross-sectional study. $J$ Clin Diagn Res 2016;10:IC01-4.

20. Hall LH, Johnson J, Watt I, et al. Healthcare staff wellbeing, burnout, and patient safety: a systematic review. PLoS One 2016;11:e0159015.

21. Zou G, Shen X, Tian X, et al. Correlates of psychological distress, burnout, and resilience among Chinese female nurses. Ind Health 2016;54:389-95.

22. Khamisa N, Peltzer K, Oldenburg B. Burnout in relation to specific contributing factors and health outcomes among nurses: a systematic review. Int J Environ Res Public Health 2013;10:2214-40.

23. Zalewska A. "The Satisfaction With Job Scale" - measurement of cognitive aspect of overall job satisfaction. Folia Psychol 2003;7:49-61.

24. Miasek P. Gender differences in job satisfaction and the quality of life in management staff. Psychol J 2015;21:305-10.

25. Emerson SD, Guhn M, Gadermann AM. Measurement invariance of the Satisfaction with Life Scale: reviewing three decades of research. Qual Life Res 2017;26:2251-64

26. Diener E, Emmons RA, Larsen RJ, et al. The satisfaction with life scale. J Pers Assess 1985;49:71-5.
27. Scheier MF, Carver CS, Bridges MW. Distinguishing optimism from neuroticism (and trait anxiety, self-mastery, and self-esteem): a reevaluation of the Life Orientation Test. J Pers Soc Psychol 1994;67:1063-78

28. Schou-Bredal I, Heir T, Skogstad L, et al. Population-based norms of the life orientation test-revised (LOT-R). Int J Clin Health Psychol 2017:17:216-24.

29. Maslach C, Jackson SE. The measurement of experienced burnout. J Organ Behav 1981;2:99-113.

30. Kleijweg JH, Verbraak MJ, Van Dijk MK. The clinical utility of the Maslach Burnout Inventory in a clinical population. Psychol Assess 2013;25:435-41.

31. Tijdink JK, Vergouwen AC, Smulders YM. Emotional exhaustion and burnout among medical professors; a nationwide survey. BMC Med Educ 2014;14:183.

32. Helkavaara M, Saastamoinen P, Lahelma E. Psychosocial work environment and emotional exhaustion among middle-aged employees. BMC Res Notes 2011;4:101.

33. Demerouti E, Bakker AB, Leiter M. Burnout and job performance: the moderating role of selection, optimization, and compensation strategies. J Occup Health Psychol 2014;19:96-107.

34. Ahmadi O, Azizkhani R, Basravi M. Correlation between workplace and occupational burnout syndrome in nurses. Adv Biomed Res 2014;3.

35. Patrick K, Lavery JF. Burnout in nursing. Aust J Adv Nurs Q Publ R Aust Nurs Fed 2007;24:43-8.

36. de Paiva LC, Canário ACG, de Paiva China ELC, et al. Burnout syndrome in health-care professionals in a university hospital. Clinics 2017;72:305-9.

37. Misiołek A, Gil-Monte PR, Misiołek H. Prevalence of burnout in Polish anesthesiologists and anesthetist nursing professionals: a comparative non-randomized cross-sectional study. J Health Psychol 2017;22:465-74.

38. Dahlin M, Joneborg N, Runeson B. Performance-based self-esteem and burnout in a cross-sectional study of medical students. Med Teach 2007;29:43-8.

39. Ferri P, Guadi M, Marcheselli L, et al. The impact of shift work on the psychological and physical health of nurses in a general hospital: a comparison between rotating night shifts and day shifts. Risk Manag Healthc Policy 2016;9:203-11.

40. Dall'Ora C, Griffiths P, Ball J, et al. Association of $12 \mathrm{~h}$ shifts and nurses' job satisfaction, burnout and intention to leave: findings from a cross-sectional study of 12 European countries. BMJ Open 2015;5:e008331.

41. Shahnazi H, Daniali SS, Sharifirad G. Job satisfaction survey among health centers staff. J Educ Health Promot 2014;3.

42. Bhatnagar K, Srivastava K. Job satisfaction in health-care organizations. Ind Psychiatry J 2012;21:75-8.

43. Damij N, Levnajić Z, Rejec Skrt V, et al. What motivates us for work? intricate web of factors beyond money and prestige. PLoS One 2015;10:e0132641.

44. Güleryüz G, Güney S, Aydin EM, et al. The mediating effect of job satisfaction between emotional intelligence and organisational commitment of nurses: a questionnaire survey. Int J Nurs Stud 2008:45:1625-35.

45. Lorber M, Skela Savič B. Job satisfaction of nurses and identifying factors of job satisfaction in slovenian hospitals. Croat Med $\mathrm{J}$ 2012;53:263-70.

46. Kędra E, Nowocień M. Stressors and the risk of professional burnout in the nurses' work. Pol Nurs 2015;3:293-306.

47. Applebaum D, Fowler S, Fiedler N, et al. The impact of environmental factors on nursing stress, job satisfaction, and turnover intention. $J$ Nurs Adm 2010;40:323-8.

48. Martinez-Martin P, Prieto-Flores ME, Forjaz MJ, et al. Components and determinants of quality of life in community-dwelling older adults. Eur J Ageing 2012;9:255-63.

49. Nemcek MA, James GD. Relationships among the nurse work environment, self-nurturance and life satisfaction. J Adv Nurs 2007;59:240-7.

50. Cimete G, Gencalp NS, Keskin G. Quality of life and job satisfaction of nurses. J Nurs Care Qual 2003;18:151-8.

51. Wysokiński M, Fidecki W, Walas L, et al. Polish nurses' satisfaction with life. Nurs Probl 2009;17:167-72.

52. Toh SG, Ang E, Devi MK. Systematic review on the relationship between the nursing shortage and job satisfaction, stress and burnout levels among nurses in oncology/haematology settings. Int $J$ Evid Based Healthc 2012;10:126-41.

53. Yazdanshenas Ghazwin M, Kavian M, Ahmadloo M, et al. The association between life satisfaction and the extent of depression, anxiety and stress among iranian nurses: a multicenter survey. Iran $\mathrm{J}$ Psychiatry 2016;11:120-7. 
54. Klajda A, Szewczyk L. Occupational burnout syndrome among psychiatric nurses. Asp Health Dis 2016;1:21-9.

55. Piko BF. Burnout, role conflict, job satisfaction and psychosocial health among Hungarian health care staff: a questionnaire survey. Int J Nurs Stud 2006;43:311-8.
56. O'Mahony N. Nurse burnout and the working environment. Emerg Nurse 2011;19:30-7.

57. Tran BX, Van Hoang M, Nguyen HD. Factors associated with job satisfaction among commune health workers: implications for human resource policies. Glob Health Action 2013;6:18619. 